\title{
Paraplegia
}

\section{Upward Displacement of the Centre of Gravity in Paraplegic Patients}

\author{
G. Duval-Beaupere, ${ }^{1}$ G. Robain ${ }^{2}$ \\ ${ }^{I}$ Directeur de recherche, ${ }^{2}$ Chef de clinique, INSERM U215, Clinique de Réeducation \\ motrice (Pr.Held). Hôpital R.Poincaré, F 92380 Garches, France.
}

\begin{abstract}
Summary
The centres of gravity of 44 complete chronic spinal cord injured patients and 24 normal subjects were measured using a gamma ray scanner (Barycentremetre). The results are expressed as a percentage of body length and as anatomical level. The mean weight of paraplegic patients was $12 \mathrm{~kg}$ less than the controls. The centre of gravity was $5 \%$ of body length higher in the paraplegic patients than in the controls, equivalent to 3 to 4 vertebrae level. The importance of such changes in the centre of gravity for the design of stable wheelchairs is discussed.
\end{abstract}

Key words: Spinal cord patients; Centre of gravity; Wheelchair stability, Sittingposition

The Barycentremetre, a gamma ray scanner (Fig. 1), provides in vivo measurement of the weight and centre of weight of successive body slices from the top of the head to the coxofemoral joints (Pascal, 1974; Duval-Beaupere, 1976). The centre of body weight supported by each vertebrae and the coxofemoral joints can be displayed on two orthogonal full-spine radiograms by using a common coordinate system for the gamma ray scans and the X-ray system (Fig. 2) (Duval-Beaupere, 1987). These data can be used to compute the weight supported by the vertebrae and the coxofemoral joints and the relationship between the vertebrae, the sacral or the bicoxofemoral axis and the centre of weight they support. The lever arm of the corresponding force may also be assessed.

The position of the centre of weight, in front or behind the vertebrae or the coxofemoral joint, requires an opposing muscle force to ensure stability of the mechanical system. Therefore, although we cannot precisely evaluate the load exerted by all the weight and stabilizing forces, we can evaluate the way in which this load varies when the anatomical relationship of the centre of weight changes following alterations in the spinal curves and pelvic tilt (Cosson, 1987). 


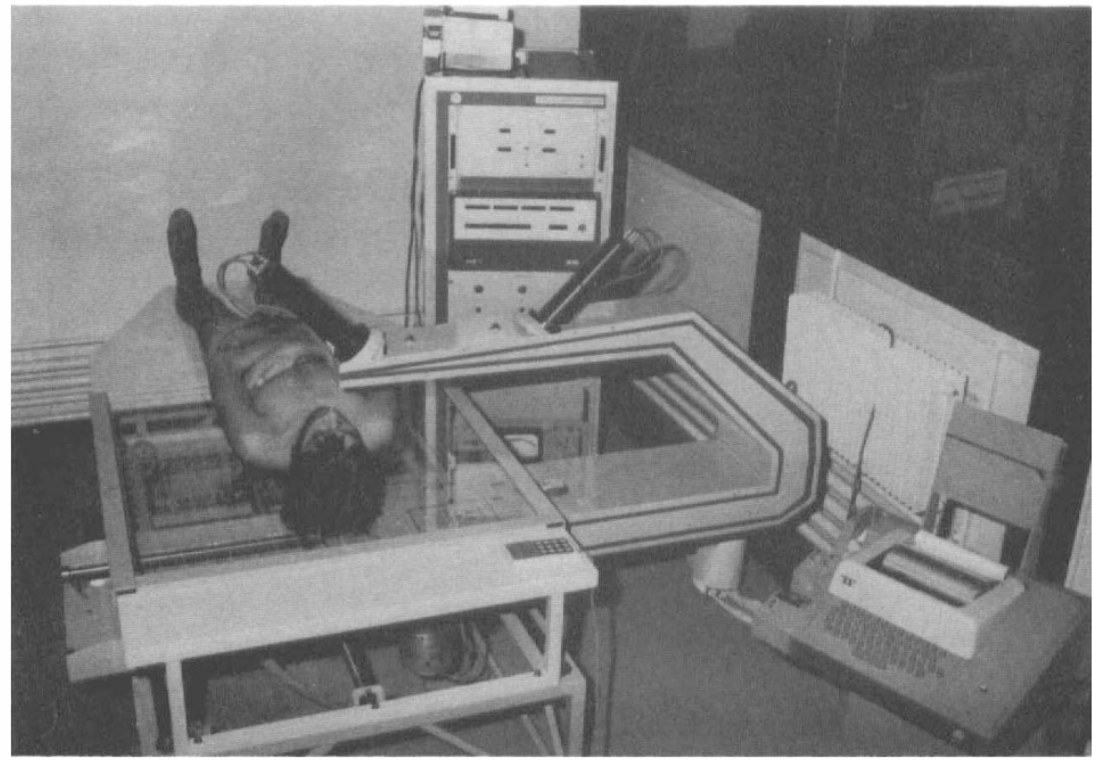

Figure 1 The Barycentremetre.

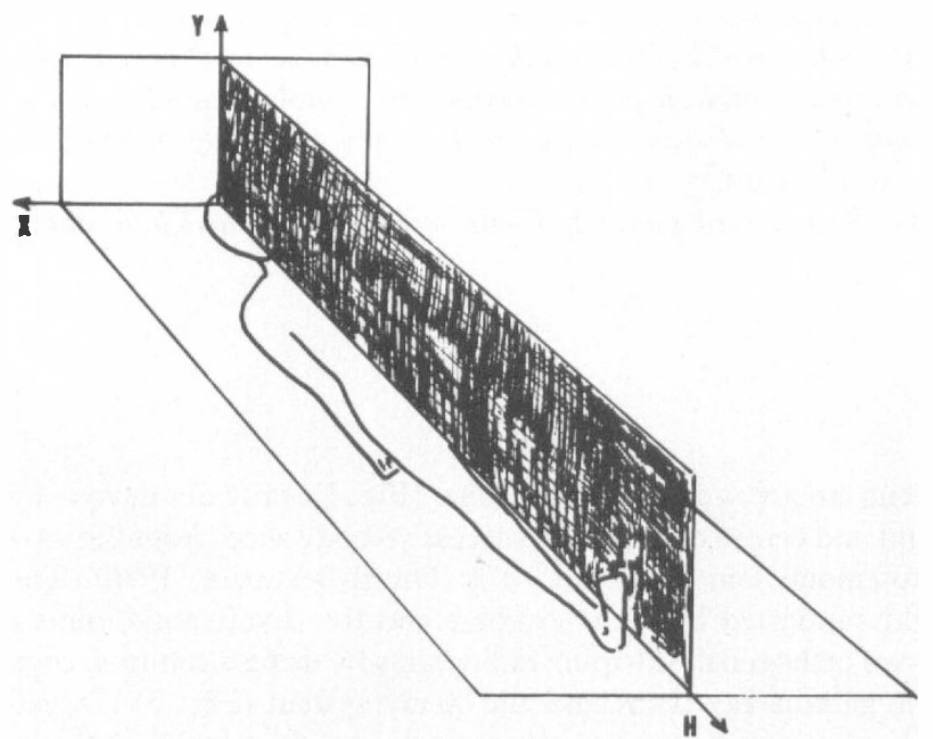

Figure 2 The coordinates system.

The sitting positions of controls (Cosson, 1987) and of paraplegic patients (Dumesnil de Maricourt, 1986) were studied using this method. This study underlined the major contribution of height and tilting of the wheelchair back in reducing the mechanical influence of lack of muscle for paraplegic patients and ensuring their stability.

The Barycentremeter's scans reported in this study provide a new data on the body segments weights and centres of weight of paraplegic patients. These anthro- 
pometric parameters constitute fundamental reference data for the further studies on the factors governing the stability and mobility of paraplegic patients.

\section{Material and methods}

Forty four adult subjects, 32 males and 12 females, (mean age 32.35 years SD 18, range 17-70 years), with chronic spinal cord lesions were studied; 42 were the result of traumatic injuries, 2 were the result of medical ischaemia, the 24 adult control subjects were selected from students and staff of the unit. Figure 3 shows

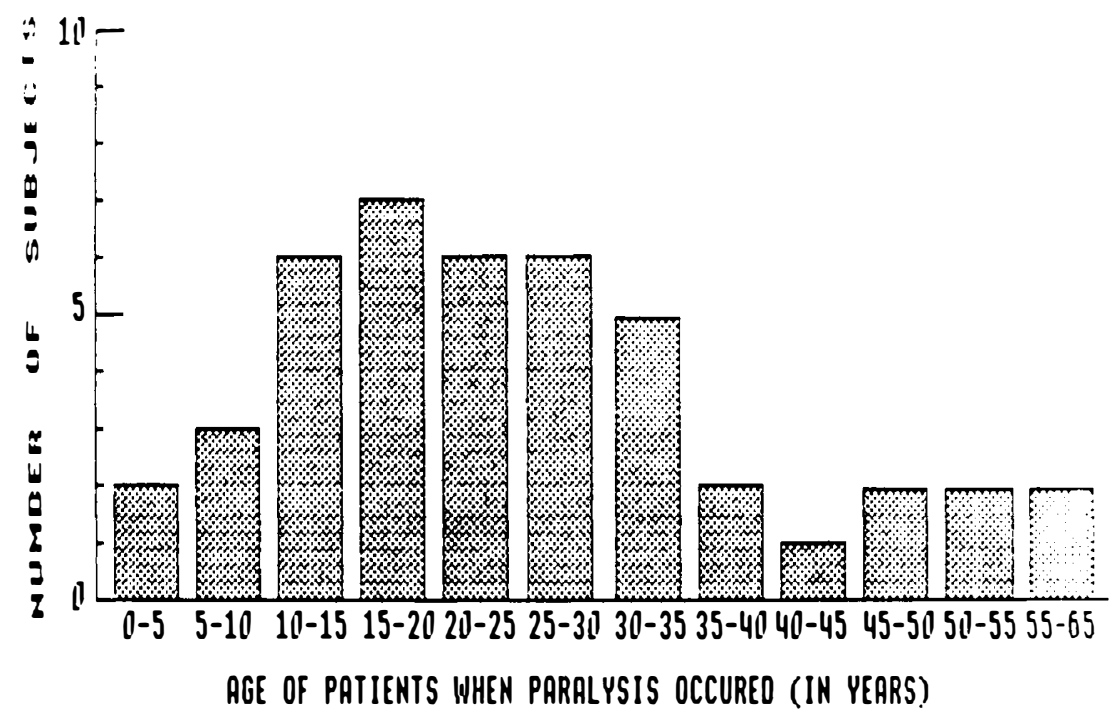

Figure 3 Patients' ages at the time of acute injury.

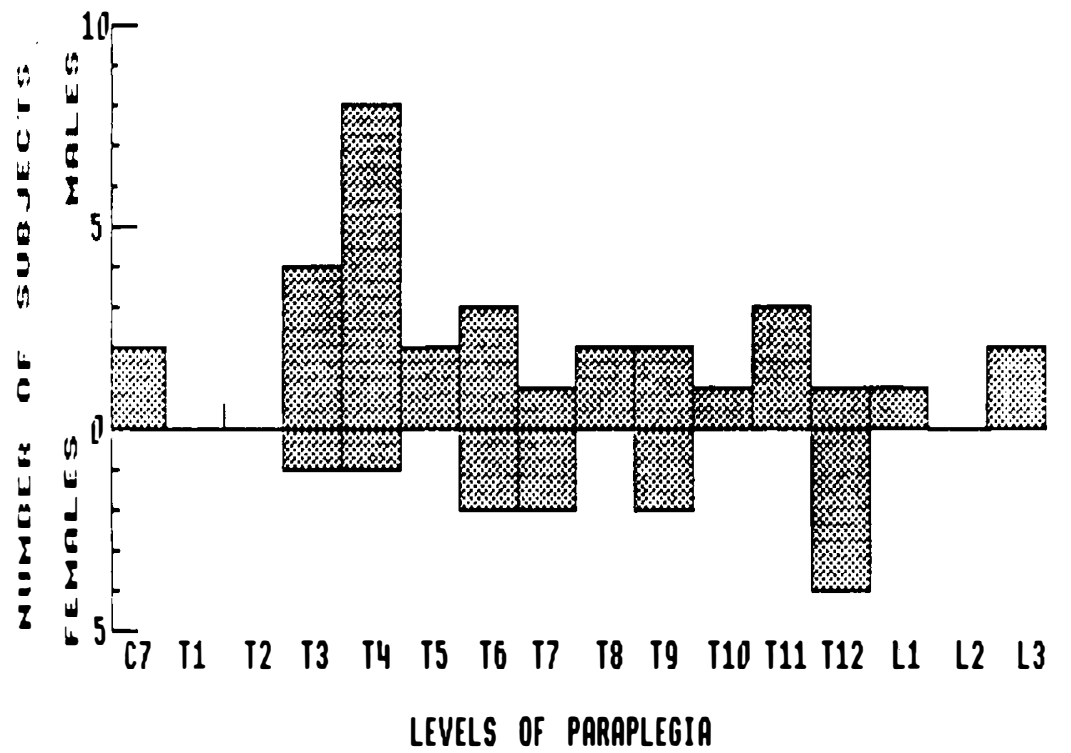

Figure 4 Upper myelomeric level for paraplegic patients. 
the patients' ages at the time of acute injury (mean 26 years, SD 15.3); Figure 4 shows the myelomeric paraplegic level for males and females. The neurological level of paralysis was determined and used in the statistical analysis. It was also quantified, by assigning a value of 1 to $\mathrm{Cl}$ and a value of 25 to $S 1$. This graded scale was used to compute the coefficient of regression between the height of the centre of gravity and the neurological level of paralysis. Figure 5 gives the time elapsed between acute injury and examination.

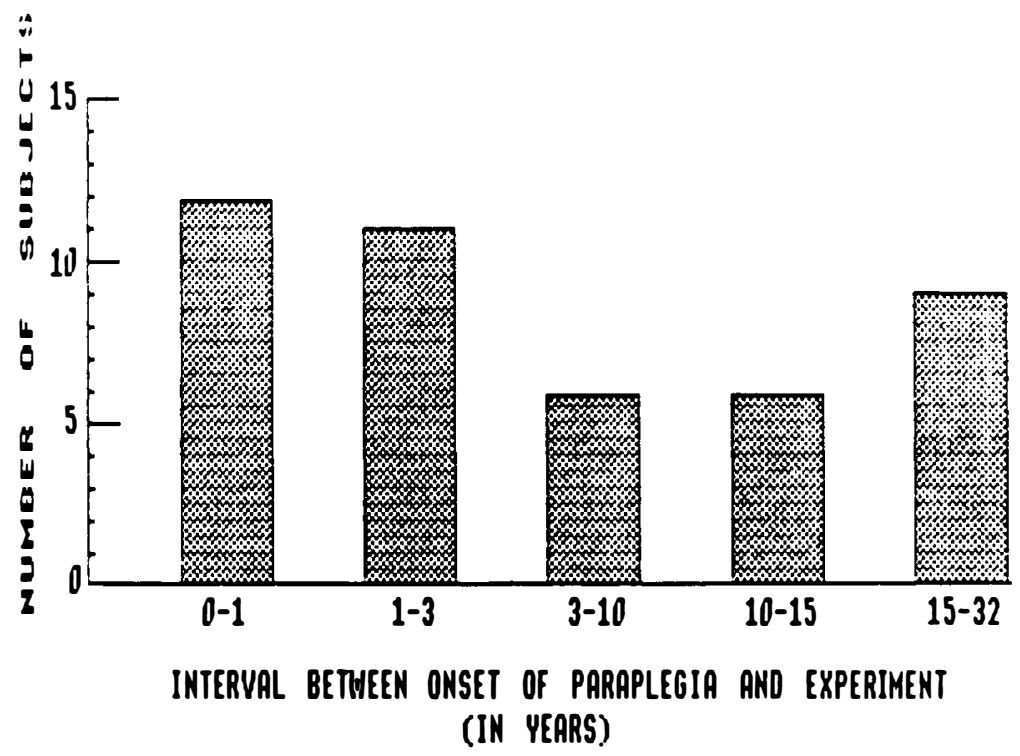

Figure 5 Time elapsed between acute injury and examination.

Table I Anthropometric data of paraplegic and control subjects

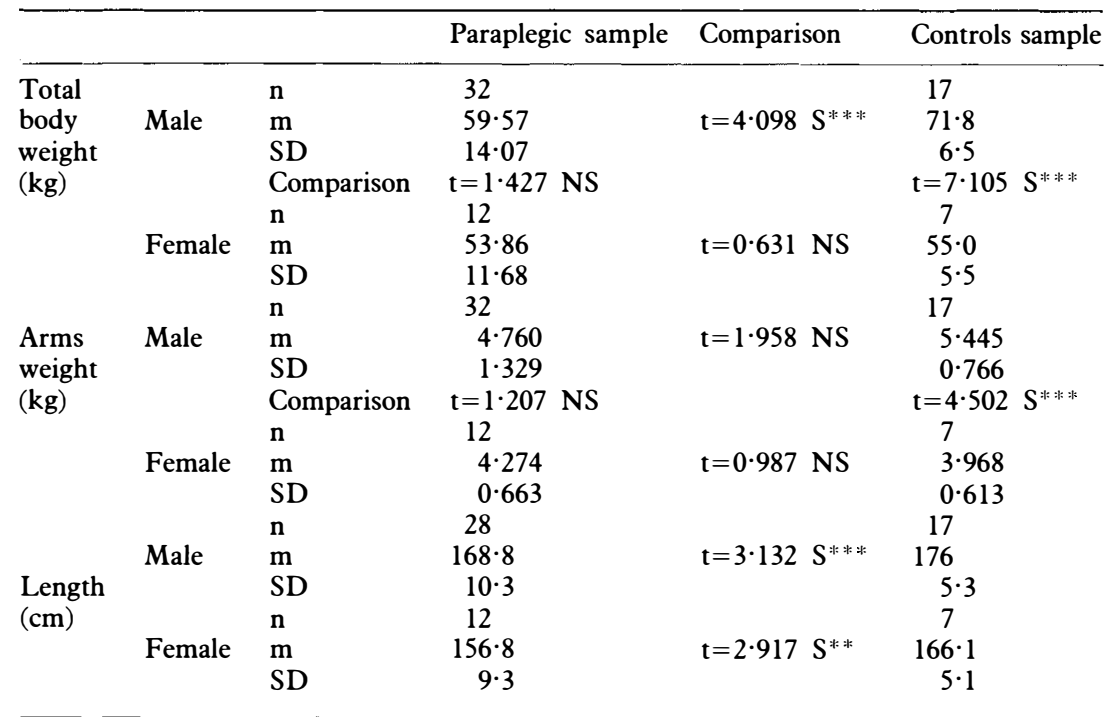

$\mathrm{n}=$ number, $\mathrm{m}=$ mean, $\mathrm{SD}=$ standard deviation, $\mathrm{t}=$ Student Fisher test, $\mathrm{s}=$ significant probability 
The mean body weight of paraplegic patients is shown in Table I. Total body length was obtained for only 40 patients, (mean value is given in Table III; 4 patients with hip deformities could not be measured.

The body centre of gravity (CG) was located using the Barycentremetre. Since the Barycentremetre provides progressive increments of the weight during scanning from the top of the head to the coxofermoral joints, the CG is the level at which half total body weight is reached. This level can therefore be expressed as a percentage of body length. The single common reference system used for Barycentremetre measurements and fullspine radiographs facilitates integration of informations from the two systems which can be used to locate the centres of weight and their expression as an anatomical level. The frontal and sagittal coordinates of CG cannot be obtained as scanning is not continued below the coxofemoral joints, but the three coordinates are obtained for the upper body segment.

Table II Height co-ordinate of CG expressed as a percentage of total body length from the top of the head, for paraplegic and control patients

\begin{tabular}{|c|c|c|c|c|}
\hline & & Paraplegic sample & Comparison & Control sample \\
\hline & $\mathrm{n}$ & 27 & \multirow{5}{*}{$\mathrm{t}=5 \cdot 174 \mathrm{~S}^{* * *}$} & 17 \\
\hline \multirow[t]{4}{*}{ Male } & $\mathrm{m}$ & $35 \cdot 9$ & & $41 \cdot 5$ \\
\hline & SD & $4 \cdot 0$ & & $1 \cdot 6$ \\
\hline & Comparison & $\mathrm{t}=1.666 \mathrm{NS}$ & & $\mathrm{t}=1.627 \mathrm{NS}$ \\
\hline & $\mathrm{n}$ & 12 & & 7 \\
\hline \multirow[t]{3}{*}{ Female } & $\mathbf{m}$ & $38 \cdot 1$ & \multirow[t]{3}{*}{$\mathrm{t}=3.482 \mathrm{~S}^{* *}$} & $42 \cdot 5$ \\
\hline & SD & $3 \cdot 3$ & & $0 \cdot 2$ \\
\hline & $\mathrm{n}$ & 39 & & 24 \\
\hline \multirow[t]{2}{*}{ Total } & $\mathrm{m}$ & $36 \cdot 6$ & \multirow[t]{2}{*}{$\mathrm{t}=5.927 \mathrm{~S}^{* * *}$} & $41 \cdot 8$ \\
\hline & SD & 3.9 & & $1 \cdot 7$ \\
\hline
\end{tabular}

( $\mathrm{n}=$ number, $\mathrm{m}=$ mean value, $\mathrm{SD}=$ standard deviation, $\mathrm{t}=$ Student Fischer test, $\mathrm{S}=$ significant probability ${ }^{*} 0.05,{ }^{* *} 0.02,{ }^{* * *}<0.01, \mathrm{NS}=$ no significant)

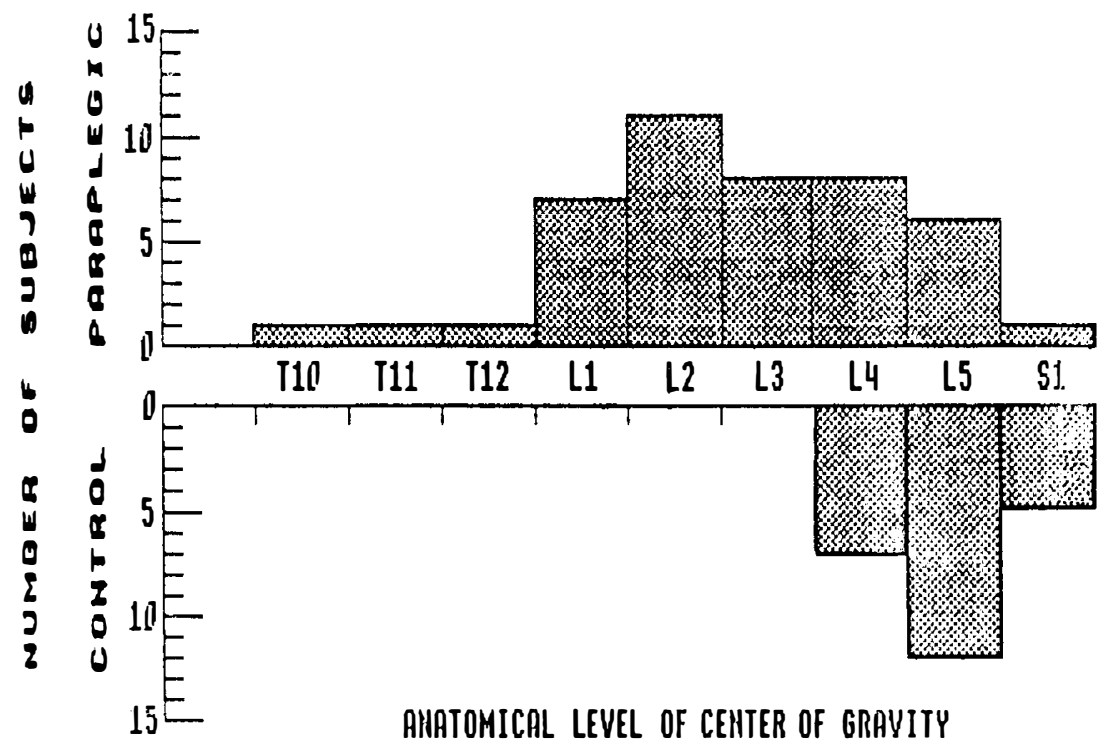

Figure 6 Anatomical level of CG for paraplegic and control subjects. 


\section{Results}

Centre of gravity

Table II shows the height coordinates of CG as a percentage of body length for both paraplegic and control subjects.

Figure 6 gives the height coordinates of CG expressed as anatomical level for paraplegic patients and control subjects.

The CG of paraplegic patients is about $5 \%$ of the body length higher than that of normal subjects (mean 8-9 cm), or, in terms of vertebral level, 3 to 4 vertebrae higher. The variation in CG position is greater in paraplegic patients than in normal subjects.

\section{Factors which may contribute to the upward displacement of $C G$}

Some basic characteristics of the patient sample were initially established by computing the regression coefficient $(r)$; the older the subject when paraplegia occurred the lower the upper level of paralysis $(r=0.365 \mathrm{~S}$, probability 0.02$)$. There was no correlation $(r=0.072)$ between the duration of paralysis (time between onset and measurement) and the upper level of paralysis or between the level of CG and the age at which paraplegia occurred. $(\mathrm{r}=0 \cdot 116)$.

Further analysis showed no correlation between the level of CG and the upper level of paralysis $(r=0.226)$ or between the level of CG and the duration of paraplegia $(r=0 \cdot 194)$.

\section{Discussion}

\section{Mass and centre of mass measurement}

The method of measuring mass and the co-ordinates of its centre in human subjects, in vivo (Pascal, 1974), was validated in an earlier study (Duval-Beaupère, 1976). The accuracy of trunk weight estimation is $1.7 \%$ and the error in centre of mass estimation is 0.50 to $1 \mathrm{~cm}$ for the height co-ordinates and $0.1 \mathrm{~cm}$ for the sagittal and frontal coordinates. The method provides measurements of the height of the CG for normal subjects which are in good agreement with those obtained by other methods on supine subjects (Duval-Beaupère, 1987).

\section{The paraplegic population}

The mean length of the paraplegic subjects is less than that of the control (normal) subjects, probably because of growth defects in some of the paraplegic patients who sustained their spinal injuries before they had reached maturity. A comparison of the mean body length of paraplegic patients injured prior to and after their seventeenth birthdays, shows a significant defect $(10 \mathrm{~cm})$ for the female patients, but no difference for the males. Similarly, there was a significant mean defect of 14 $\mathrm{kg}$ in the body weight of female paraplegic patients injured prior to 17-years-ofage, while the male paraplegic patients were heavier than the controls. This may indicate a genetic difference between the male paraplegic population and its control, since we have shown that paraplegic children have growth defects (DuvalBeaupère, 1983). Such a difference may also explain the lack of correlation between the age of paraplegia and mature body length in this specific group of paraplegic patients. Other factors, such as loss of height of a fractured vertebra, or loss of disc 
thickness in the paralysed spine, may contribute to the shorter body length of paraplegic patients.

\section{Centre of gravity}

The CG tends to be higher in paraplegic patients than in normal subjects, perhaps because of a loss of weight from the paralysed body segment following cord injury. Thus, the CG level should be correlated with the upper level of paralysis, but no such correlation was found.

There may be two reasons for this lack of correlation: the random extension of the spinal cord injury, and variations in the upper limb weight. The spinal cord injury results in the death of a variable number of medullary cells, which is reflected in a peripheral neurological syndrome, the lesional syndrome.

The lesional syndrome occurs from the upper level of paralysis to a variable lower level and produces severe amyotrophy. The extent of this syndrome varies from one subject to another in a manner which is independent of the upper myelomeric level of paralysis and of time elapsed since initial paralysis. The neurological syndrome is central, immediately below the peripheral lesional syndrome, and produces less amyotrophy. Unfortunately, the extent of these syndrome were not measured in this group of subjects.

Paraplegic patients also rely heavily on their upper limbs; any resulting increase in the weight of their arms independent of the upper level of paralysis. The Barycentremetre technique includes an evaluation of arm weight, which is shown on Table III. There was no difference between the arm weights of male and female paraplegic patients, but the arms of male controls were heavier than those of female controls. Mean paraplegic arm weight was not greater than that of controls. The sample examined may have been too small to show any statistical difference, but the shorter body length of paraplegic patients may also have contributed to the result.

Consequently, we have no means of assessing the contribution of either the lesional syndrome or arm weight to the higher position of the CG in paraplegic patients.

There was no correlation between the higher level of CG in paraplegic patients and the duration of paraplegia. The physical condition of paraplegic patients in the initial 6 months after the onset of paraplegia precludes any examination during this period. Hence, within this limitation, we can assume that muscular atrophy occurred early, within the initial 6 month period. A random extension of the lesional syndrome may also occur after this period.

\section{Consequences for the sitting position and wheelchair stability}

Paraplegic patients are sitting patients, but the methodology used in this study does not allow measurements to be made on subjects in this position. Santchi (1963) measured the CG for a group of patients in both the supine and sitting positions and showed that it moved with the postural change. The CG of sitting subjects, when expressed as a percentage of body length, was $6 \cdot 1 \%$ higher and $6 \cdot 1 \%$ further forward than the CG of the same subjects in a supine position. We cannot assess the exact rise of CG for sitting paraplegic patients but we can determine whether these upper and forward displacements are greater or smaller than those of controls. We therefore measured the weights and centres of weight of all the body 
Table III Data for paraplegic and control patients measured up to the hip joint

\begin{tabular}{|c|c|c|c|c|c|c|}
\hline & Units & Paraplegic & Comparison & Control & & \\
\hline $\begin{array}{l}\text { Total } \\
\text { body } \\
\text { weight }\end{array}$ & $\mathrm{kg}$ & Female & $\begin{array}{l}\mathrm{n} \\
\mathrm{m} \\
\mathrm{SD} \\
\text { Comparison } \\
\mathrm{n} \\
\mathrm{m} \\
\mathrm{SD}\end{array}$ & $\begin{array}{l}12 \\
58 \cdot 6 \\
13 \cdot 8 \\
\mathrm{t}=1 \cdot 165 \mathrm{NS} \\
5 \\
50 \cdot 6 \\
10\end{array}$ & $\mathrm{t}=2.339 \mathrm{~S}^{*}$ & $\begin{array}{c}7 \\
71 \cdot 3 \\
4 \cdot 5 \\
\mathrm{t}=2 \cdot 126 \mathrm{NS} \\
3 \\
62 \\
10\end{array}$ \\
\hline $\begin{array}{l}\text { Body } \\
\text { length }\end{array}$ & $\mathrm{cm}$ & Male & $\begin{array}{l}\mathrm{n} \\
\mathrm{m} \\
\mathrm{SD} \\
\text { Comparison } \\
\mathrm{n} \\
\mathrm{m} \\
\mathrm{SD}\end{array}$ & $\begin{array}{l}12 \\
166 \cdot 4 \\
9 \\
t=1 \cdot 658 \mathrm{NS} \\
5 \\
159 \\
6 \cdot 4\end{array}$ & $\mathrm{t}=1.843 \mathrm{NS}$ & $\begin{array}{c}7 \\
5 \cdot 2 \\
173 \cdot 3 \\
\mathrm{t}=1 \cdot 779 \mathrm{NS} \\
3 \\
166 \cdot 3 \\
7\end{array}$ \\
\hline $\begin{array}{l}\text { Body } \\
\text { weight } \\
\text { above }\end{array}$ & $\mathrm{kg}$ & Male & $\begin{array}{l}\mathbf{n} \\
\mathbf{m} \\
\mathrm{SD} \\
\text { Comparison } \\
\mathrm{n} \\
\mathrm{m} \\
\mathrm{SD}\end{array}$ & $\begin{array}{l}12 \\
39 \cdot 1 \\
9 \cdot 9 \\
\mathrm{t}=1 \cdot 371 \mathrm{NS} \\
5 \\
32 \cdot 5 \\
6 \cdot 1\end{array}$ & $\mathrm{t}=1.080 \mathrm{NS}$ & $\begin{array}{c}7 \\
43 \cdot 3 \\
3 \cdot 1 \\
\mathrm{t}=3 \cdot 682 \mathrm{~S}^{* k *} \\
3 \\
34 \cdot 4 \\
4 \cdot 5\end{array}$ \\
\hline $\begin{array}{l}\text { hip } \\
\text { joint }\end{array}$ & $\begin{array}{l}\% \text { of } \\
\text { body } \\
\text { weight }\end{array}$ & Female & $\begin{array}{l}\text { n } \\
\text { m } \\
\text { SD } \\
\text { Comparison } \\
\text { n } \\
\text { m } \\
\text { SD } \\
\text { n } \\
\text { m } \\
\text { SD }\end{array}$ & $\begin{array}{l}12 \\
66 \cdot 6 \\
6 \cdot 3 \\
\mathrm{t}=0 \cdot 604 \mathrm{NS} \\
5 \\
64 \cdot 8 \\
2 \cdot 5 \\
17 \\
66 \\
5 \cdot 5\end{array}$ & $\begin{array}{l}t=2.999 S^{*} \\
t=2.984 S^{* *}\end{array}$ & $\begin{array}{c}7 \\
60 \cdot 7 \\
3 \cdot 3 \\
\mathrm{t}=0 \cdot 524 \mathrm{NS} \\
3 \\
59 \cdot 6 \\
2 \cdot 1 \\
10 \\
60 \cdot 4 \\
2 \cdot 8\end{array}$ \\
\hline $\begin{array}{l}\text { Centre } \\
\text { of } \\
\text { body } \\
\text { support } \\
\text { by } \\
\text { hip } \\
\text { joint }\end{array}$ & $\begin{array}{l}\% \text { of } \\
\text { mass } \\
\text { body } \\
\text { length } \\
\text { from } \\
\text { the } \\
\text { top }\end{array}$ & Female & $\begin{array}{l}\text { n } \\
\text { m } \\
\text { SD } \\
\text { Comparison } \\
\text { n } \\
\text { m } \\
\text { SD } \\
\text { n } \\
\text { m } \\
\text { SD }\end{array}$ & $\begin{array}{l}12 \\
25 \cdot 1 \\
1 \cdot 5 \\
\mathrm{t}=5 \cdot 154 \mathrm{~S}^{\text {*k*k }} \\
5 \\
29 \cdot 1 \\
1 \cdot 3 \\
17 \\
26 \cdot 3 \\
2 \cdot 3\end{array}$ & $\begin{array}{l}t=2.773 \mathrm{~S}^{*} \\
\mathrm{t}=0.673 \mathrm{NS}\end{array}$ & $\begin{array}{c}7 \\
26 \cdot 8 \\
0.5 \\
\mathrm{t}=0.340 \mathrm{NS} \\
3 \\
26.9 \\
0.4 \\
10 \\
26.8 \\
0.5\end{array}$ \\
\hline $\begin{array}{l}\text { Centre } \\
\text { of mass } \\
\text { lower } \\
\text { segment }\end{array}$ & & & & $56 \cdot 6$ & & $63 \cdot 4$ \\
\hline
\end{tabular}

segments supported by the hip joints in 17 paraplegic patients and 10 control subjects. The results are shown in Table III.

The mean body weight of paraplegic patients was $12 \mathrm{~kg}$ less than that of the controls. Of this total, $10 \mathrm{~kg}$ of the difference was attributable to the lower body segment and only $2 \mathrm{~kg}$ to the upper body segment. The total body CG level and the upper body segment CG level were used to compute the lower body segment level for both paraplegic and control patients; the results are shown in Figure 6. The 
lower body CG of paraplegic patients was higher than that of controls, this upward displacement of CG reflects a disproportional loss of lower body weight, mainly from the legs.

These data were used to compute the displacement of the total body CG, when the subjects moved from the supine to the sitting position with the legs maintained in an extending position. We used the data of Contini (1972) inducing that the body segment above the femoral joint is $47 \%$ of the total body length, and the displacement of the CG is expressed as a percentage of the body length. The CG of control subjects moved $6.8 \%$ upward and forward, while the CG of paraplegic patients moved $3 \cdot 5 \%$ upward and forward. The CG of normal subjects moves $6 \cdot 1 \%$ upward and forward when patients move from the supine to the sitting position (Santchi, 1963). If the legs are extended, the CG moves an additional $0.7 \%$ upward and forward. Since the legs of paraplegic patients are less heavy, the CG moves upward and forward less than $0 \cdot 7 \%$ when the sitting paraplegic patient extends his or her legs. Consequently, we may postulate that the CG of paraplegic patients moves about $3 \%$ when the patient moves from the supine to the sitting position, Thus, the CG is $33 \mathrm{~cm}$ above the seat of a normal male patient of height $174 \mathrm{~cm}$ and $37 \mathrm{~cm}$ above the seat for a paraplegic patient of similar height. It is also $19.5 \mathrm{~cm}$ in front of the seat back for the normal patient and $14 \mathrm{~cm}$ in front of the seat back for the paraplegic patient.

Such an upward displacement of the CG of a paraplegic patient must inevitably lead to a less stable wheelchair. The greater the upward displacement of CG, the more a small rise in the frontal wheels of the chair will induce a shift backwards in the CG and thus risk moving the CG beyond the axle of the rear wheels of the chair. As heavy wheelchairs are undesirable, the design of the chair itself requires examination and modification, especially the shape of the seat back and the position of the main wheels, to ensure maximum stability of the patient wheelchair unit. This is particularly important for unsporting or old patients who do not usually practice 'wheelies'. The upward displacement of CG must also be taken into account in the design of sport equipment and car seats intended for paraplegic patients.

\section{References}

Contini R 1972 Body segment parameters, Part II. Artificial Limbs 16:1-19.

Cosson P, Desmoineaux P, Robain G, Duval-Beaupere G 1987 Valeurs inertielles des segments corporels supportés par les vertèbres. Fournal of Biophysics and Biomechanics Sup. 1. 11, 52-53.

Cosson P 1987 Evaluation personnalisée des efforts exercées sur les étages vertèbraux dorsaux et lombaires de l'homme en position debout et assise. Memoire pour le DEA de Bioméchanique et de physiologie du mouvement. Université de Paris XI.

Dumesnil De MARICOURT 1986 La position assise à long terme chez le paralegique. Mémoire de DEA de sciences et techniques appliquées aux handicaps. Université de Dijon, France.

Duval-Beaupere G, Ovazza D, Tisseau J, Pascal A, Roche P, Csakvary E 1976 Mise au point d'un appareillage de mesure de la masse de segments corporels et de son point d'application. INSERM, Colloque de synthèse d'action thématique $\mathrm{n}^{\circ} 6$ : $165-177$

Duval-Beaupere G, RoBain G 1987 Visualization on full spine radiographs of the anatomical connections of the centres of the segmental body mass supported by each vertebra and measured in vivo. International Orthopaedics 11:261-269.

Duval-Beaupere G, Lougovoy J, Trocellier L, Lacert PH 1983 Trunk and leg growth in children with paraplegia caused by spinal cord injury. Paraplegia 21:339-350.

Pascal A, Csakvary E, Porte P 1974 Barycentremetre MCG10, Notice technique. CEA SES/PUP/ SERF: 74-720.

SANTCHI WR, DUboIS J, Oмото C 1963 Moments of inertia and centres of gravity of the living human body. Technical documentary report NO-TDR-63-36. Wright-Patterson Air Force Base Ohio: 1-60. 